\title{
Uma antropologia nativa da família verde-e-rosa ou conceito nativo. Por que ver rizoma onde nos mostram uma magueira frondosa?1
}

\author{
Ana Carneiro
}

\begin{abstract}
resumo Ao iniciar pesquisa de campo no Morro da Mangueira, recebi o alerta: "você tem que ter compromisso, dar um retorno para a comunidade". Relatavam-me que o "patrimônio cultural da Mangueira" vinha sendo "roubado" por "gente da sociedade". E, ao relacionar as noçóes de "comunidade" e "sociedade", explicavam-me, "a Mangueira é uma família". O artigo explora este discurso mangueirense, ouvido em geral nos espaços de interface entre "comunidade" e "sociedade". Ali, a noção de "família verde e rosa" serve de eixo a partir do qual se recompóem noçôes características à produção discursiva das ciências sociais, tais como "patrimônio cultural", "comunidade" e "sociedade". Esta ideia particular de "família", formada por não-consanguíneos, é frequentemente descrita como "uma árvore cheia de frutos" e aciona um modelo particular de relaçáo de alteridade, fazendo surgir na análise conceitos como os de rede e rizoma. Mas por que ver rizoma se nos mostram uma árvore?
\end{abstract}

palavras-chave Morro da Mangueira. Patrimônio cultural. Conceito nativo. Favela. Família. Rede.

\section{O retorno do patrimônio}

Este artigo baseia-se em pesquisa etnográfica realizada ao longo de 15 meses (de setembro de 2004 a dezembro de 2005) nos quais se desenrolou o processo de criação do Centro Cultural Cartola (CCC), situado no Morro da Mangueira. Uma de minhas últimas idas a campo foi por ocasião da inauguração oficial do CCC $^{2}$. Entretanto, desde minha entrada naquele universo, algumas atividades culturais já vinham se desenvolvendo ali e meu trabalho de campo consistiu entáo em ajudar a realizar tais atividades, graças ao que fui declarada por meus interlocutores como parte da "família verde e rosa”, conforme veremos adiante. Este termo faz parte de todo um vocabulário do parentesco usado na Mangueira frequentemente (mas não exclusivamente) em referência a relações não biológicas. A terminologia "familiar" é necessariamente inclusiva, embora seja acionada preponderantemente (não exclusivamente) em um ambiente onde há forte presença de pessoas que - como eu - vieram de fora da Mangueira atraídas pelos aspectos sociais e culturais encontrados ali. Adiante, procurarei mostrar como a noção de "família verde rosa" articula-se a uma concepção particular - podemos dizer "nativa" - de termos que integram o senso comum do vocabulário antropológico e que são, cada vez mais, apropriados pelos projetos sociais e culturais característicos do ambiente que pesquisei ${ }^{3}$.

Composto por palavras como "cultura", "comunidade, "sociedade", "identidade", "patrimônio cultural”, e daí por diante, aquilo que Bruno Latour (2006) identificou como "vocabulário do social”, é encarado aqui como um vocabulário "nativo". A relação deste discurso com o discurso das ciências sociais (ou "do social", para falar como o autor) não ser entendida como dada, e nisto reside nosso problema. Meu foco, portanto, está lançado sobre 
o que se produz em um ambiente de interface entre as relaçôes sociais entendidas como "comunitárias" e aquelas estabelecidas com o que os mangueirenses chamam "sociedade". Minha hipótese é a de que a maneira como as relações são assumidas e relatadas ali guarda uma continuidade com a dinâmica relacional encontrada no alto do morro, embora o que aconteça em um desses dois ambientes não possa ser entendido como idêntico ao que se passa no outro. No espaço dos projetos culturais, por exemplo, cabe perguntar em que termos se dá a relação entre quem é do morro e quem é de fora? Existe ali uma desigualdade suposta, poderíamos imaginar. No entanto, como já nos lembrou Maria Laura Viveiros de Castro Cavalcanti (1999, p.8) em seus ensaios sobre o carnaval, "os limites de processos culturais não são necessariamente os mesmos limites das classes e camadas sociais". É neste sentido que a ideia de "família verde e rosa" assume papel fundamental em na análise a seguir. Da mesma forma, justifica-se aqui a ênfase dada a indivíduos que - "nascidos e criados" na Mangueira - circulam e ganham posição de destaque entre as pessoas da "sociedade". Ao menos quando se encontram em determinados locais de produção cultural! $\mathrm{O}$ fato de que aqueles mangueirenses - muitas vezes definidos por nós como "mediadores" - tenham, em relação aos seus vizinhos, um acesso privilegiado sobre o "patrimônio cultural verde e rosa”, não deve ser usado para deslegitimar seu discurso. Pois justamente, o mesmo discurso reaparece no alto do morro entre os que se queixam por não ter o mesmo acesso, e então se reivindicam "parte da família”. Darei adiante alguns exemplos pontuais de minha experiência no morro da Mangueira, apenas com o intuito de mostrar em que medida a imagem da relação familiar operante ali é replicada no ambiente onde se situa o Centro Cultural Cartola, um ambiente de "fachada", conforme definiu um de meus informantes. Trata-se, portanto, de tentar entender como esta "fachada" é capaz de subsumir e deslocar, sem, contudo, anular, relações normalmente lidas na chave da classe social e/ou da raça. Trata-se, em suma, de buscar ver como os mangueirenses são criativos e potentes em seus modos de recompor o sentido da diferença vivida entre eles e "a gente da Zona Sul" (da "sociedade").

Sobre a avenida, o viaduto que passou a se chamar "Cartola" por decreto municipal; e sob o viaduto, uma cabine policial. Ali acontecem atividades esportivas e culturais, além de cursos profissionalizantes e técnicos diversos; todos destinados às crianças e jovens "carentes" que a "sociedade" quer ver serem cuidados. É um lugar de fachadas vistosas. Poder-se-ia dizer também um cartão de visitas da Mangueira: políticos, artistas, jornalistas, "gente da Zona Sul" - "gente da sociedade" - vêm aos eventos públicos promovidos pelas organizações "sociais" e "culturais" situadas nessa espécie de área fronteiriça entre o "morro" e a "rua". Tal ambiente descreve-se na paisagem formada por três estabelecimentos que abrigam entidades não-governamentais voltadas para projetos sociais e culturais: o Grêmio Recreativo Escola de Samba Estação Primeira de Mangueira, o Complexo Vila Olímpica da Mangueira e o Centro Cultural Cartola. Este último, embora menos expressivo do que os dois primeiros no que se refere ao tempo de existência e ao montante de recursos de que dispóe, chama atenção pela grandiosidade de sua sede, uma construção até então abandonada, onde funcionava uma das fábricas que se deslocaram dali para "fugir da violência”. Vizinhos, os três grandes estabelecimentos localizam-se de frente para a avenida asfaltada, circundando parte do Morro da Mangueira e suas fachadas, sempre recém- pintadas de verde e rosa. Contrastam com barracos sem reboco e vielas estreitas logo acima. Sua riqueza é ostensiva e muitas vezes ressaltada pelos moradores da Mangueira que, entre 
críticas e distanciamentos ao que se passa ali, não deixam de elaborar discursos que vangloriam a "família verde e rosa", para então marcar seus pertencimentos à mesma. As palavras de desacordo também marcam disputas entre as diretorias das três entidades, cujas atividades, patrocinadas por empresas - em geral estatais - são realizadas em nome de um mesmo "patrimônio cultural". Falando-me certa vez sobre as discórdias, um mangueirense ponderou a dimensão do conflito explicando-me que, ali, "é que nem família: todo mundo briga toda hora, mas não deixa de ser irmão por isso”. Era apenas mais uma entre as inúmeras vezes nas quais ouvi ali termos ligados à ideia de família serem usados para qualificar relaçóes humanas em geral.

Ao chegar pela primeira vez no Morro da Mangueira com o intuito iniciar pesquisa de campo, recebi o alerta: "você tem que ter compromisso, dar um retorno para a comunidade, e não fazer como todas essas pessoas que vêm de fora para se aproveitar e depois vão embora" E me relatavam que o "patrimônio cultural" da "comunidade" vinha sendo roubado por gente da "sociedade". Fotografias composiçóes musicais, cartas pessoais e objetos usados em desfiles e shows de samba dos mangueirenses constituíam o "patrimônio cultural" que, de acordo com os relatos de moradores da Mangueira, deixavam as casas do morro para se tornarem relíquias de alto valor econômico nas mãos de jornalistas, pesquisadores e outros amantes da história cultural carioca. "A Mangueira é uma família verde e rosa”, explicaram-me, logo naquele primeiro encontro, contrapondo as noçôes de "comunidade" (detentora legítima do patrimônio) e de "sociedade", que vem de fora para roubá-lo. Já naquela ocasião, entretanto, a noção de "família verde e rosa" logo apareceu para efetuar uma operação oposta à da oposiçáo entre pessoas da comunidade e da sociedade. A mesma pessoa a me alertar so- bre o retorno do patrimônio tratou de elogiar o homem que me trouxera até a Mangueira, apresentando-me aos meus primeiros informantes: apesar de ser de fora da comunidade, era um irmão, fazia parte da família verde e rosa, escutei então. Meu conhecido ocupava um cargo de confiança em um órgão estadual e pertencia a um seleto conjunto de pessoas que, na Mangueira, engajam-se ao longo de anos em relaçôes pessoais envolvendo seja campanhas políticas, seja ações ligadas aos "projetos sociais" ali realizados. Sobe o morro quase todo final de semana para tomar uma cerveja, comer um churrasco, contaram-me. Tem gente que é assim, nunca morou na Mangueira, mas já faz parte da família.

A fronteira entre comunidade e sociedade, ou entre "nós" e "eles", é uma questão de precisão conceitual - quem se inclui ou se exclui e de que maneira isto ocorre quando se diz "parte da família”. Estaria a família verde e rosa delimitando as mesmas fronteiras definidas pela ideia de comunidade? Neste caso, por que incluir na família quem não vive na comunidade? Que direito esses novos membros familiares poderiam ter sobre o patrimônio cultural da comunidade? Entramos assim na arena de discussóes a respeito de alguns dos conceitos centrais no pensamento antropológico. O "vocabulário do social", de acordo com Latour (2006) (entre muitos outros autores), teria perdido sua força devido ao uso excessivo. Ter-se-ia tornado frouxo ou demasiado fluido. Seriam palavras vazias usadas com o intuito meramente estratégico de auto-legitimação para obtenção de recursos disponibilizados por políticas culturais ${ }^{5}$. Desde o início e, depois, de modo reincidente, as palavras que definiram os ambientes e participaram das relaçóes do meu trabalho de campo eram as mesmas que constituem uma espécie de germe da discórdia da antropologia. Os debates teóricos acusam-nas frequentemente de serem 
"essencializadas" à medida que ultrapassam os limites e o rigor da disciplina acadêmica.

O que fazer quando o "outro" produz discursos cujas palavras são também as dos "nossos” próprios discursos? O maior risco é o de cairmos em uma desconstrução que pretenda recuperar o percurso pelo qual tais palavras teriam sido ressignificadas. Pois se esta empreitada tem por condição a crença em um conceito "original", "completo", ela reforça um certo lugar incômodo para os antropólogos, tantas vezes diagnosticado por eles mesmos: no mesmo movimento em que acusam o "assujeitamento" de quem eles pesquisam, buscam "dar-lhes voz", assumindo para si o direito exclusivo de manipular o "verdadeiro" significado das coisas. Além do mais, este percurso em retrocesso corre o risco de nos levar em direção ao que já sabíamos previamente. E a antropologia - não devemos nos esquecer - se faz justamente pelo efeito da teoria antropológica quando aplicada sobre a experiência de outras teorias, de lógicas não previstas pelo nosso arsenal analítico (Wagner, 1981, p.29-30). Ou, ainda, como disseram Trondman e Willis em seu Manifesto for Ethnography, alimentamo-nos do efeito promovido pela experiência etnográfica, da surpresa provocada por uma experiência insuspeita, causando em nossa teoria uma espécie de ah-ha effect (Trondman e Willis, 2000, p.15).

Tal efeito ocorreu, no meu caso, quando notei que a ideia de patrimônio cultural está, na Mangueira, quase colada à definição que me foi dada como "parentesco afetivo", conforme veremos. Esta união imprevista entre uma categoria cultural e uma posiçáo sociológica orientou-me a observar como o uso de determinados clichês das ciências sociais não é um mero artifício estratégico para fins políticos, mas a incorporação legítima de termos que fazem sentido naquele universo particular, o que envolve interesses políticos tanto quanto questôes de ordem afetiva; o domínio do pú- blico tanto quanto o do privado. Assim, cabe aqui eleger algumas das noçôes cuja articulação nos aponta possíveis caminhos para tratar, do ponto de vista mangueirense, o problema das fronteiras conceituais ora mencionados: "patrimônio cultural mangueirense", "comunidade" e "sociedade", adiantando-se que eles me parecem eloquentes porque acionam imediatamente um modelo particular de relação de alteridade. Ou seja, tais palavras dão forma a uma "antropologia nativa". Poderíamos dizer "ocidental nativa", pois faz reverberar uma "arqueologia do discurso dominante nas ciências sociais" (cf. Sahlins, 2004 [1996], p. 564), engajando alguns dos conceitos centrais ao nosso discurso dominante. Mas o repertório de palavras articuladas através do discurso da "família verde e rosa" ultrapassa os termos ora listados. Não é à toa, por exemplo, que a ideia de "patrimônio" evoca a de "propriedade" e de "pertencimento", e também as articula a palavras como "direito", "roubo", "compromisso", “ajuda”, "criação" e "rede”. Assim, é justo entender que esta antropologia é "nativa” também porque "selvagem", para falar como Lévi-Strauss (2004 [1962]), pois resulta de um engenhoso trabalho de bricolagem e produz caminhos de análise distintos dos que estamos habituados.

Não se deve menosprezar o fato de que os termos a integrar esta antropologia nativa são homônimos de categorias analíticas cujo uso já se generalizou a ponto de se tornar senso comum. Pode-se mesmo contestar meu ponto de partida recusando-se a homonímia em favor da homologia. De um lado de outro, na Mangueira ou nas ciências sociais, tratar-se-ia dos mesmos significados. Mas se minha proposta aqui é negar o ideal platônico de um conceito original, puro, é não apenas porque busco uma perspectiva não-hierárquica em um contexto de produção discursiva no qual, como antropóloga, é suposta uma posição de vantagem. A proposta parte também de minha própria 
experiência de campo, no qual ficou evidente que, embora falássemos a mesma língua, nem sempre (ou quase nunca) nos entendíamos. Neste sentido, vale nos remetermos à colocaçáo de George Marcus (2009, p. 13-34) a respeito da necessidade estética de uma nova mis-en-scène na escrita antropológica: a cena malinowskiana do encontro etnográfico em uma praia deserta não corresponde mais às situaçóes de campo atuais. "O cenário e as fronteiras do trabalho de campo [...] emergem por meio da observação de um conjunto de relaçóes, de uma paisagem social que é tanto material quanto imaginária" (Marcus, 2009, p. 24). A ideia de que a etnografia é uma experiência no sentido artístico do termo, de produçáo de efeitos, diz o autor, já está em trabalhos pioneiros como Malinowski, Firth, Evans-Pritchard e outros (idem, p. 27). Se hoje as realidades locais conectam-se virtualmente com um espaço a rigor ilimitado, como fazer para delimitar o "campo"? A proposta de Marcus é transformar a cena do encontro, "ou reconfigurá-la por dentro de seus próprios termos. Num sentido, essa é uma tarefa de tradução" (idem, p. 18-19). Como em uma performance artística realizada em colaboraçáo, prossegue ele, o trabalho de campo seria assim "um meio de articular uma reinvenção da tradição, dentro de seus próprios termos", buscando os elos criados por outrem a partir dos efeitos de nossa presença. Este artigo é um experimento neste sentido: foi a partir das relaçóes que estabeleci ali, que pude acionar um problema metodológico de maior alcance, aproximando-me de um discurso alheio sem reduzi-lo ao previsível.

\section{2. "Nascido e criado"}

Para explicitar seu vínculo privilegiado com o local onde vive e se afirmar como autêntico membro da comunidade, o mangueirense lan- ça mão da fórmula "nascido e criado". Manifesta assim, por exemplo, o direito de fazer parte das atividades do G.R.E.S. Estaçâo Primeira de Mangueira, o que em princípio implicaria a participaçáo tanto nos seus processos decisórios quanto no prestígio e lucro financeiro gerados por tais atividades. Até que ponto as pessoas nascidas e criadas na Mangueira exercitam esse direito, contudo, é uma questáo capaz de gerar prolongadas controvérsias entre os mangueirenses. Em 1928, a Escola de Samba da Mangueira foi - ela também - "nascida e criada" no Morro. Hoje, no entanto, a rede de pessoas e aparatos técnicos responsáveis pelos rumos da Escola - seu sucesso, sua saúde - fomenta-se em grande parte fora da comunidade, por pessoas da Zona Sul, lugar dos ricos, acusa-se, lugar da sociedade. É precisamente contra isto que pesam as reivindicaçóes de pertencimento e as acusaçóes contra o roubo cometido por quem vem de fora: identifica-se como auto-evidente que o "patrimônio cultural" pertence àqueles que são nascidos e criados no morro.

$\mathrm{Na}$ Mangueira, a criação de crianças costuma incluir uma rede de relaçóes estabelecidas em torno de determinada casa, ultrapassando os limites da família nuclear ou mesmo das relaçóes de sangue. Pontos de referência em uma ampla área de vizinhança, algumas casas da Mangueira vivem cheias de gente. Sob o comando de uma mulher, a dona da casa, em geral com larga experiência na criaçáo de seus próprios filhos, tais pontos sáo conhecidos em todo o morro como "a casa da tia Fulana", ou "a casa da vó Fulana". São as chamadas "tias" e "vovós de criação". Muitas vezes, ouvi a ênfase dada à importância desses laços através de uma formulação curiosa. Diziam-me "Fulana é minha tia de criação, mas é mais tia que a minha tia de verdade". Os mangueirenses que se relacionam no espaço de uma casa da tia (ou vovó) frequentemente dão continuidade a uma história familiar - seus vínculos se estendem entáo a um tempo ante- 
rior aos seus nascimentos. Graças ao cotidiano na casa da "tia", ou da "vovó", quando as mães saem para trabalhar e deixam ali sua prole, ou nos almoço de domingo e nas tardes de brincadeira, pessoas crescem lado a lado, compartilhando experiências de ordens diversas. A comensalidade, a rotina, as referências de espaço são uns dos elementos que definem modos de existência comum, cuja convergência constantemente gera "frutos": filhos, sobrinhos e netos futuros. $\mathrm{Na}$ intimidade gerada por meio daquele espaço doméstico, dar-se-á conta de criar gente. Assim, ao longo das geraçôes, as relaçôes de convivência diária desde a infância ao redor de um determinado domicílio dão continuidade a relações anteriores. Nesta intimidade, criam-se também afetos, e não raro são os casos daqueles que, criados juntos na infância, enamoram-se ao amadurecer ${ }^{6}$.

Algumas etnografias recentes vêm explorando a ideia de "criação" como essencial ao laço de parentesco, sendo, portanto, tão primordial quanto o fato biológico gerado pelo intercurso sexual (cf. Bamford, 2004; Bodenhorn, 2000 e Edwards, 2000, entre outros). Esta perspectiva é importante aqui à medida que possibilita desvincularmos a natureza das relaçóes familiares mangueirenses de um substrato biológico correlato e necessário, mas é preciso notar que a ideia de "criação", no morro, não se reduz aos acontecimentos posteriores ao ato sexual. Noutras palavras, a rede em questão é responsável pela criação do próprio nascimento.

Quando - alguns meses após aquele primeiro encontro e o alerta dirigido a mim Celso declarou que eu havia entrado para a "família verde e rosa" (numa referência às cores da Escola de Samba da Mangueira), notei que o vocabulário do parentesco com que então se elaborava minha inclusão no campo associava-se, também ali, a uma ideia de criação. Apesar do tom efusivo em que foi anunciada minha inclusão na comunidade, meu amigo manguei- rense ressaltou a necessidade do "compromisso" a ser assumido por mim, o que se desvelaria sempre sob a forma de uma condição: que eu desse "o retorno à comunidade". Assumi então diante dele o compromisso de escrever o nome de todos os mangueirenses que ajudassem em minha pesquisa para o "livro", como ele chamava minha dissertação de mestrado. A autoria de meu trabalho distribuía-se assim entre aqueles que eram - pretendera eu - justamente o objeto desta autoria. E a oposição entre o sujeito-autor e seu objeto de pesquisa mostrava-se equivocada, afinal, se a investigação antropológica era mais um dentre os produtos gerados pelo "patrimônio cultural mangueirense", ela deveria estar implicada na "criação" deste patrimônio, nunca à sua revelia.

Os trabalhos que me passaram a ser solicitados envolviam necessariamente um "resgate cultural", isto é, o "registro dos fatos passados". "Pesquisar os verdadeiros fatos do passado" para trazê-los às "novas geraçôes", nisto residia o que Celso me apresentou como "trabalho de resgate cultural”. Visando planejar tarefas, entregou-me uma lista com os nomes de pessoas que eu deveria entrevistar e filmar. Explicou-me com gravidade: "aqui está o verdadeiro patrimônio cultural da Mangueira”. Olhei a relação de nomes e observei que quase todos eram precedidos pelos termos "tia(o)" e "vovó(ô)". Fiz o comentário e ele respondeu: "é um tratamento afetivo, como se fosse um parente, mas afetivo". A conexão entre as noções de "patrimônio cultural" e "parentesco afetivo" mostrou-se então uma boa pista para entender do que se tratava, afinal, a "família verde e rosa”. Podendo ser entendida como invenção e fabricação de patrimônios tal qual a Escola, mas também como sustento e alimentação de crianças - a palavra criação reúne os elementos que me fizeram entrar para a "família verde e rosa”. Se minha pesquisa consistia em criar (e manter) o elo com aquela cadeia produtiva, por 
este caminho, e sob esta condição, eu era incorporada pela "família". Mas estava eu sendo também incorporada à "comunidade"?

A declaração sobre minha inserção na família verde e rosa ocorreu depois que eu passara uma temporada de dez dias dormindo e comendo na "casa da Zica", como o lugar é reconhecido pelos moradores da Mangueira. Zica foi esposa do sambista Cartola, com quem morou durante muitos anos na casa que ficou conhecida como ponto turístico, situada ao lado da quadra de ensaios da Escola de Samba. Com a morte deles, Regina, filha de Zica, tornou-se a dona da casa em que me recebeu. Dez dias podem parecer insignificantes para um trabalho de campo "sério", mas foram determinantes para a maneira com que me aproximei de alguns moradores dali. Aquela temporada marcou de maneira significativa minha mobilidade no morro, até entáo restrita ao asfalto ao pé do morro. Foi depois da participação na produção cultural mangueirense e do envolvimento afetivo e rotineiro com os moradores da Mangueira que me ouvi pertencendo à "família verde e rosa".

Mas se minha inclusão implicava certo direito, note-se que este nunca deixou de ser condicionado pelo meu "retorno à comunidade". Meu direito seria sempre limitado. Há pessoas para quem, ao contrário, tais direitos e pertencimentos são naturais e, portanto, inalienáveis. Mesmo a estas, o direito sobre o patrimônio da Mangueira, tal como o pertencimento à comunidade, "vem de nascença", mas não prescinde de uma "criação". O patrimônio cultural deve ser herdado por quem o criou no duplo sentido, isto é, gerou e manteve. É portanto em nome desta criação se desenrolam as rotineiras controvérsias: os argumentos contra as figuras de destaque na produção cultural da Mangueira fundam-se no fato de que tais pessoas, "cresceram graças à Escola" e agora não moram na "comunidade". Assim, se, à primeira vista, a noção de "sociedade" está em relação de oposição com as ideias de "comunidade" e esta coincide com a de "família", isto se transforma quando a primeira é englobada pela última. Incluir (e excluir) quem possui o patrimônio e pertence à família implica complexas teorizações nativas sobre modelos de relações de diferença; seja de englobamento, seja de oposição. O que está em jogo é a "labilidade" de noçôes que, usadas para diferenciar sujeitos coletivos ou individuais, trazem elementos imprevistos às fronteiras que definem (cf. Herzfeld, 1996). As dificuldades de definição das "identidades" - ou "pertencimentos" - ressurgem então na esteira de uma ordenação nativa que nem sempre corresponde às delimitaçóes previamente estabelecidas.

\section{3. "Social" ou "cultural"?}

Nascido e criado no Morro da Mangueira, Celso foi a primeira pessoa que conheci durante a pesquisa de campo. Trabalhava então como coordenador social do Projeto Social e Esportivo Vila Olimpica da Mangueira, e, assim que fomos apresentados, manifestou ânimo para "estabelecer uma troca" comigo. Depois de marcar com estes termos o início de nossa relação, perguntou-me, a guisa de nos preparar um "organograma da pesquisa": "você quer estudar o lado social ou o lado cultural, folclórico da Mangueira?" Ambas, respondi ainda sem clareza sobre minha própria pesquisa. Celso mostrou-se satisfeito com a resposta e prosseguiu com algumas afirmaçóes sobre a relação da comunidade com a "cultura" e a "sociedade". Em conversas futuras com outras pessoas da Mangueira, o interesse sobre a vida "social" e/ou "cultural" do local investigado era o que se esperava de mim. Minha prática antropológica parecia então se encerrar na escolha do tipo de material - social ou cultural - escolhido para dar ordem às informaçóes já ordenadas, isto é, 
aos dados (de campo) já informados por categorias que pareciam organizar tanto o pensamento antropológico quanto o nativo. $\mathrm{O}$ que me restaria então a investigar?

Pensei em uma terceira alternativa: lançar o foco longe do discurso nativo sobre a cultura e a sociedade, descrevendo a vida mangueirense onde ela ignorasse o "vocabulário do social". Com efeito, este discurso fazia-se menos presente à medida que eu me afastava dos ambientes de interface entre a "comunidade" e a "sociedade" ". Tal universo não me parecia muito autêntico. $\mathrm{Na}$ ocasião, contudo, considerei significativo o fato de que a auto-descrição associada à imagem "sociocultural" da Mangueira surgia em absolutamente todos os momentos nos quais eu era apresentada a um morador dali. Tal imagem, ao mesmo tempo em que estabelecia a priori a oposição entre os moradores da "comunidade" e o universo ao qual me associavam (o da "sociedade"), colocava-me em pé de igualdade com eles no que se refere à teoria analítica que lhes diz respeito. Mostravam assim conhecer minha linguagem para, deste modo, mostrar que não falávamos a mesma língua.

Quando Celso reagiu à minha proposta de estudar conjuntamente os aspectos "sociais" e "culturais" da "comunidade", acionou a fórmula "a Mangueira é uma árvore frondosa", dizendo-me: "sim, é isso! Uma árvore gera muitos frutos saborosos, mas, pra continuar assim, tem que ter o tronco bem sustentado! Quer dizer, tem que ter o lado social, mas também tem que ter a raiz, a cultura, o folclore". A imagem da árvore reapareceria no desenho de uma mangueira em tonalidades de verde e rosa pendurado à parede da quadra de ensaios da Escola, e também em livros, discos e material midiático em geral ("registros culturais"). Nestas reproduções da árvore verde e rosa, os nomes de cada um dos chamados "baluartes" da Escola figuram sob as raízes. "São ancestrais, raízes que sustentam o tronco da Mangueira”, explicaram-me. Sobre o tronco, os galhos da árvore apresentam nomes de personalidades mangueirenses - famosas por terem-se tornado "patrimônio cultural". $\mathrm{Na}$ árvore genealógica verde e rosa, não constam entretanto os nomes dos frutos; eles ainda estão por vir, constituem a geração futura, escutei.

Espera-se que esses anônimos - crianças e jovens nascidos e criados no Morro, integrantes dos projetos sociais e culturais da Mangueira - se transformem futuramente em nomes que integrarão a Escola, ajudando a mantê-la, criando e fazendo vender seus produtos culturais. Quem sabe serão esses nomes serão também "patrimônio cultural". De todo modo, esses "filhos da Mangueira" devem hoje salvaguardar o "patrimônio cultural" do qual são "herdeiros", o que se faz também por via de uma certa prática de criação. Como disse Celso sobre seu trabalha com projetos: "os jovens da comunidade, é tudo filho meu”. Mais tarde, eu ouviria os rapazes dizerem que Celso é "tio mesmo". Para alguns, "é quase um pai”: ajuda, dá conselho, dá bronca.

Celso foi quem me estimulou a desenvolver a pesquisa no Centro Cultural Cartola e quem me ofereceu a ideia de transformar algumas tias e vovós "do morro" em tias e vovós "do samba”, isto é, a ideia de fazer com elas registros culturais que as transformassem em patrimônio cultural, tal como outras. Transformar em História as histórias pessoais. Assim, cheguei ao CCC por intermédio de Celso, que me apresentou a Nilcemar e Pedro, ambos netos de Cartola e definidos por Celso, como seus "irmãos". Mais tarde, tomei conhecimento que tal estatuto familiar era diferenciado em relaçáo a um e outro, na mesma medida em que se diferenciava o poder de gestáo de cada um desses no patrimônio cultural verde e rosa. Igualmente, distinguia-se entre eles a história de relação com Zica e Cartola. 
Cartola não apenas foi um dos fundadores da Escola como também escolheu as cores verde e rosa para representá-la, além de ser o compositor de seu primeiro samba-enredo. Ainda hoje sua criação musical mantém-se reconhecida, o trabalho de Dona Zica (como é conhecida na "sociedade"), ou "Tia Zica" (na "comunidade"), é considerado por todos um fator determinante para que o músico tenha se tornado um "patrimônio cultural verde e rosa": os cuidados dedicados pela esposa de Cartola foram "sempre sábios e generosos", conforme ouvi ali frequentemente ${ }^{8}$. Nilcemar repetiu-me estes adjetivos ao relembrar o período em que morou com seus avós Zica e Cartola em uma casa em Jacarepaguá (fora da Mangueira, portanto). Àquela época, contou-me a neta, ela aprendeu a administrar e receber amigos frequentadores das "famosas feijoadas de Dona Zica". Havia nessas ocasiōes "muitos nomes da cultura" e da "sociedade". Esta é a rede de amigos até hoje cultivada por Nilcemar; sua "herança mais valiosa", conforme sua própria elaboração, o que implica um cuidadoso trabalho de manutenção (ou "criação"). Desta rede, nascem a notoriedade e o reconhecimento de Nilcemar, sem igual entre os outros herdeiros legais?. Quando morou com os avós, dedicou-se por anos a cuidar da agenda de compromissos de Zica e Cartola, tornando-se - graças a esta "ajuda" - "conhecida e respeitada na sociedade". Segundo o anedotário mangueirense, a casa de Jacarepaguá é uma referência na história da "redescoberta" que jornalistas e artistas fizeram diante da "comunidade da Mangueira". Após a morte de Cartola, Zica retornou à sua antiga casa, no Morro, onde hoje vive sua filha Regina, mãe de Nilcemar. O retorno é narrado por esta quando recorda da avó e de seu "carinho especial pela comunidade". O retorno não fora motivado por questôes financeiras, destaca a neta; foi um "retorno afetivo" à comunidade, elaborou.
A repetiçấo da ideia de retorno à comunidade me chamou atenção. Por que exigiram de mim o retorno do patrimônio cultural à comunidade se este é valorizado justamente à medida que circula na sociedade? Noutras palavras: por que reivindicar para si o que se oferece aos outros? Ora, na criação do patrimônio mangueirense, como na criação de uma criança, o direito sobre o objeto de cuidados está no próprio gesto de "dar" cuidados. O que se dá, em suma, é a própria relaçáo, e nisto dar implica sempre receber. A analogia entre a criação familiar e a do patrimônio cultural evoca novos contornos também sobre a ideia de produçáo do parentesco. "Eu preciso manter a rede de relaçōes que herdei de meus avós pra manter vivo nosso patrimônio cultural", explicara Nilcemar. A "rede" à qual se refere garante, a um só tempo, que o patrimônio se mantenha "vivo" e que ela mantenha seu direito de herdeira; direito de quem cuida.

Neste sentido, é significativo que Nilcemar seja neta consanguínea de Zica, mas não de Cartola, que era estéril e, portanto, năo deixou herdeiros biológicos. Este dado é raramente mencionado pelos mangueirenses, e ainda mais raro é ouvi-lo com o intuito de deslegitimar o "direito" Nilcemar. Para fundamentar acusaçóes de desmerecimento contra ela, o que se costuma é lembrar dos anos em que Cartola viveu com outra mulher, convivência que daria "direito" também aos herdeiros desta última e não apenas aos de Zica. Em defesa própria, Nilcemar destaca o vínculo privilegiado que guardou com Zica e Cartola durante a adolescência e início da vida adulta. "Fui a única neta a ter esse privilégio", repete. A experiência integrou-a a uma rede de intelectuais e artistas em torno dos avós - rede hoje cultivada por Nilcemar com o zelo próprio de uma filha pródiga. Nilcemar é herdeira do "direito" sobre o "patrimônio cultural" reconhecido pelos nomes de Zica e Cartola. A despeito de seus 
irmãos de sangue e mesmo de sua mãe Regina, filha biológica de Zica. Regina explica que não gosta de "receber gente", "não puxei à minha mãe, Nilcemar foi quem puxou".

\section{Temas de combinação: história e História}

Como se diz frequentemente em Mangueira, "branco só sobe o morro para comprar droga”. Pensando nisto, perguntei ao estagiário do Centro Cultural Cartola o que ele entendia por "família verde e rosa". "Essa história de família", respondeu, "é tudo fachada. As pessoas falam isso para não falarem dos problemas que a Mangueira tem”. Repliquei: então por que você diz que Celso é "um pai”? O rapaz respondeu-me: "está certo, tem gente que realmente faz parte daquilo, vive pr'aquilo. É... Tem gente que realmente faz aquela família... Não sei te responder, vou pensar mais...”. É interessante que a ideia de família verde e rosa, embora associada ao "ambiente de fachada", "para a sociedade", apareça também para qualificar vínculos pessoais internos ao morro.

Mimetizando o vocabulário de tantas outras fontes de informação - a conversa com amigos, o noticiário nacional, o noticiário criminal, a indústria fonográfica, a produção acadêmica especializada e daí por diante - a imagem da família mangueirense é mesmo como uma "fachada". Noutras palavras, um clichê. Entender por aí a imagem da árvore verde e rosa não é um equívoco, mas nos prende ao problema de confundir um artifício descritivo - uma forma de "objetificação" - com as relações implicadas na criação deste artifício. Parar por aí seria reduzir as relaçóes que eu me dispus a descrever ao objeto produzido por elas. Quanto de informação pode-se desejar em um mundo que tem sempre dados em demasia e, portanto, quase nenhum dado (Strathern, 1999, p. 4)? Como avaliara o estagiário, é preciso pensar mais.

Resgatemos a história de vovó Lucíola, uma senhora com então 104 anos a quem Celso me levou para que fizéssemos um trabalho de "registro cultural", resgatando a "pré-história da Mangueira"10. "Todo mundo conhece a Mangueira depois da criação da Escola de Samba, mas ninguém fala de antes", explicou-me ele, e então desenhou uma linha cortada ao meio por um traço indicando o ano de 1928, ano de criação da Escola. Durante a visita à vovó Lucíola, ouvi dela e de Celso sobre a importância do termo "vovó" para sua ampla autoridade e reconhecimento no Morro, "seja bandido ou policial, todo mundo conhece, mas tem que dizer vovó, se não ninguém sabe quem é”. $\mathrm{Na}$ ocasião, Lucíola explicou-me que não é "da mesma gente" de "Tia Zica” e não participou, como esta, da História escrita sob as luzes da Escola de Samba da Mangueira. Ressaltou, contudo, que mantiveram boas relaçóes ao longo de suas vidas; "mas cada uma era dona do seu pedaço". Ao redor de suas respectivas casas, gravitam redes distintas. A importância do espaço das casas centradas na figura de "tias" e "vovós" chama atenção para o fato de que, sendo ou não registradas na "História" do Morro, a autoridade exercida por elas define um território público situado no interior da esfera doméstica.

Sugiro que esta ideia dá forma à dinâmica do "parentesco afetivo". Este se constitui por um processo de constante fabricação das formas de relação, um modo inclusivo de se relacionar, de atualizar, através da convivência, uma memória que se faz partilhada. Como vimos, a rede familiar verde e rosa estende-se por uma história de relaçóes passadas que está direta e inevitavelmente ligada ao nascimento de dada pessoa, bem como ao seu futuro. A criação, pela convivência em um contexto doméstico, de uma memória coletiva comum, anterior aos nascimentos, figurando-se como a própria ori- 
gem, familiar e afetiva, de cada indivíduo nascido e criado ali - conforme vimos acontecer nas casas das tias - parece se replicar na maneira com a qual os membros da comunidade incorporam a gente da sociedade. Em ambos os contextos, a natureza da relação - seja ela representada pela consanguinidade, no primeiro caso, ou pelo local de origem, no segundo - é eclipsada pela criação da mesma. Note-se ainda que esta criação não constitui uma transformação da natureza originária, mas sim a própria condiçẫo do fato originário. Ter uma tia afetiva é identificar-se com ela não porque ela fez de seu sobrinho afetivo um ser diferente do que prescrevem seus laços sanguíneos, mas sim porque a relaçáo com seus pais biológicos teve origem em uma história anterior, a um passado remoto na "casa da tia". A criação do parentesco afetivo é então, por definição, anterior ao nascimento e prolongada ao longo da vida. $\mathrm{Da}$ mesma forma, a incorporaçáo de uma pessoa da sociedade à família verde e rosa depende de uma criação que se estende no tempo, depende de um retorno. Em um caso como no outro, o direito sobre a "herança" (familiar ou cultural) não obedece à lógica da linhagem, mas se condiciona a um compromisso constantemente projetado no futuro. Neste compromisso reside a própria manutenção do laço. Se eu não era "nascida" na Mangueira, que eu fosse de algum modo criada ali. Ao ajudar no "resgate" da História mangueirense, criei então minha própria história.

O "parentesco afetivo" não é, portanto, um modelo de relação que prescreve determinada forma de se relacionar, ele está antes na própria forma de fazer relação. Como coloquei inicialmente, a "família verde e rosa" é uma chave para notar como certas relaçôes destituídas de um fundo biológico (separado e referido a um dado sistema de classificação do parentesco) participam de uma "ordem natural" das coisas, uma ordem de relaçóes que se espera em con- tínua reprodução ao longo das novas geraçóes. Assim, a ideia de ser "mais tia do que a tia de verdade" implica dar, ao que a tradição acadêmica nomeia de "social", uma força própria ao que costumamos ver como "fatos da natureza". Desta forma, podemos acrescentar à argumentação a maneira como a imagem de uma identidade negra é criada e recriada como elemento próprio às relaçóes comunitárias e familiares da Mangueira. Na memória das feijoadas de Dona Zica, por exemplo, reencena-se a "origem" do que hoje se reconhece como "comunidade negra". Por esta perspectiva, a definição de raça negra pode ser equiparada à de "família", menos por seu componente sanguíneo, biológico, do que pelo trabalho de "criaçáa" que se lhe associa. Um trabalho que se repete na história contada e recontada, vivida e revivida: os negros vindos de navio da Bahia, recém alforriados, foram outrora acolhidos por "tias" donas das casas localizadas na zona portuária do Rio de Janeiro. Como a lendária Tia Ciata, repetem-me os mangueirenses frequentemente. Depois, diz a História, foram deslocados para os morros. As marcas desta trajetória precisam ser resgatadas em forma de histórias pessoais, para então se tornarem História. Nisto consistia a ajuda e o retorno que me eram solicitados por Celso e também por Nilcemar.

Deste modo, a produção coletiva dos "registros" - orais, escritos, audiovisuais - que transformam história em História criam a um só tempo um importante "resgate" e uma "família afetiva". É neste sentido que a linguagem familiar é essencialmente inclusiva. Como em uma família biológica, entretanto, existem cores, posiçóes e direitos variados.

Chegamos assim ao ponto para o qual convergem as conotaçóes da terminologia do parentesco, seja esta usada quando se "sobe o Morro", seja no ambiente da Escola, "na rua". Note-se, por exemplo, que a quadra de ensaios da Escola tem como nome oficial "Palácio do 
Samba" e costuma ser identificada pelos mangueirenses como "a casa da comunidade". Ali, celebram-se casamentos, aniversários de debutantes e outras datas marcantes das vidas de pessoas nascidas e criadas na Mangueira. Nos ensaios e shows abertos ao público, cobra-se o preço de qualquer casa de espetáculos da valorizada Zona Sul da cidade, mas "a comunidade" tem acesso gratuito por uma porta exclusiva, onde um segurança, necessariamente morador da Mangueira, faz a triagem apenas checando o rosto de quem passa. "A quadra de ensaios é nossa", explicam-me os que ali foram nascidos e criados. $\mathrm{Ou}$, ao menos, "devia ser", reclamam. Da mesma forma, as "tias do Morro", donas de casas, deveriam ser todas "donas do palácio do samba"; o trabalho de resgate histórico de Vovó Lucíola proposto por Celso tinha este argumento de fundo. De fato, muitas dessas "tias" e "vovós" são "tias e vovós do samba" e, portanto, "donas do palácio do samba". O estatuto da Escola de Samba da Mangueira prevê a "ala das tias", que não desfila durante o carnaval mas é considerada fundamental para o bom andamento dos ensaios na quadra. Significativamente, sua presidente na época da pesquisa era uma das filhas de "Tia Neuma”, já falecida e também listada como "patrimônio da comunidade”. As relaçôes criadas com a "sociedade" na quadra, espaço "do samba", não podem prescindir de alguém que saiba "cuidar da casa”. Assim, no Palácio do Samba, "cria-se” uma rede não só de pessoas, mas de "resgate cultural", "trabalho social" e formas de "retorno"; toda uma "cadeia produtiva" de relaçôes nas quais as "tias do morro", "tias afetivas" se tornam "tias do Samba”, "patrimônio cultural”. Transformação comparável à de um "barraco do morro" em "palácio"11. Ao conectar a imagem do "parentesco afetivo" à do "patrimônio cultural”, a árvore verde e rosa funciona como uma espécie de "tema de combinação" (cf. Jean-Klein, 2003): reúne o que costuma- mos separar entre os domínios do "social" (as "tias"), do "cultural" (o "patrimônio") e da "natureza" (o "sangue").

\section{Coda}

É preciso ir mais devagar à tarefa de olhar a “composição do social", escreve Latour (2007, p. 208). A respeito dos "limites do patrimônio", Reginaldo Gonçalves (2007) também sugere cautela. Propóe "dirigir nosso olhar na direção dessa complexa rede de agentes e de instituiçóes mediadores do patrimônio [...]", pois estes não são suportes neutros (Gonçalves, 2007 , p. 244 - grifo meu). No processo de construção de instituiçôes "situadas entre a memória e a história”, tais como o "patrimônio cultural", reflete ele, ocultam-se "as ambiguidades das categorias sensíveis" vinculadas aos contextos nos quais os patrimônios emergem e graças aos quais ganham sentido. Neste processo, favorece-se a criação de "categorias abstratas", com fronteiras nitidamente delimitadas (Gonçalves, 2007, p. 246). Ao argumentar que devemos tornar visível o que costuma ser ocultado nos debates sobre patrimônio cultural, o autor ressalta que a própria ideia de "mercado" não é exterior aos "bens" que constituem o "patrimônio", mas qualificada pelos mesmos (Gonçalves, 2007, p. 242).

A questão dos "limites" do patrimônio aproxima-nos assim da noção de "rizoma" deleuzeguattariana: de um lado, esta "rede de mediadores" leva em consideração regimes de não-signos, como na formulação de Deleuze e Guattari (2004). Com isto, entende-se que as formas de reprodução do Capital incluem "produção de desejo", ou, para usar a expressão de Gonçalves (ANO?), "categorias sensíveis". De outro lado, este ponto de vista analítico opóe-se ao que os dois primeiros autores definiram como modelo da "árvore", aquele que 
nos permite enxergar nossos nativos de cima, sem entretanto ver nada além de cópias ("galhos bifurcados") dos pressupostos conceituais que carregam, argumentam eles (Deleuze e Guattari, 2004). Quando nos deparamos com modelos nativos desconfortavelmente próximos aos nossos o problema se complica. Neste caso, não há como lançar mão de uma hierarquia de perspectiva legitimada pelo esforço de "distanciamento analítico". O conceito de "rizoma" entraria em cena entáo para dar densidade às relaçôes de diferença que alimentam a produção de conhecimento antropológico ${ }^{12}$.

Os "sistemas rizomáticos" são agenciamentos maquínicos: constituem-se por elos de ligação de naturezas diversas. E assim o são os regimes de signos postos em jogo - incluem estados de não-signos (Deleuze, 2003). Um baile funk, por exemplo, pode ser entendido como "agenciamento", e é também um "sistema” que envolve não só a relação entre o funkeiro, a música e seus companheiros de baile; envolve ainda aspectos como o volume em que o som é tocado e o aparato tecnológico que o viabiliza. Assim, meu caminho de análise consistiu em observar o que acontece quando determinadas palavras são agenciadas em um ambiente determinado, entrecruzando-se com os componentes singulares das vidas com as quais tive contato na Mangueira. Mas por que ver rizoma se os mangueirenses nos falam tanto de certa árvore frondosa? Por que definir como "rede" (de criação) uma "família” que se mostra na imagem de uma "árvore"? Noutras palavras, podemos perguntar: não estaria minha análise sugerindo que os instrumentos analíticos escolhidos por mim (como "rede", "agenciamento", "máquina”, "rizoma” e "ANT”) seriam apenas mais uma "tecnologia de ponta", usada em detrimento dos já desgastados termos empregados pelos "nativos" (como "árvore", "comunidade", "sociedade" ou "patrimônio cultural")? Seria o modelo da "rede" a priori mais adequado à realidade?
Nem todo mundo desenrola, conecta e corta as mesmas questóes nos mesmos lugares e segundo os mesmo princípios, observa Strathern (1996, p. 531). Perseguindo a rede de um processo de definição do direito de patente, a autora descreve a maneira como o fluxo de pessoas e coisas envolvidas numa invenção científica é interrompido de acordo com a definição do proprietário da invenção. A quem pertence o direito de propriedade, depende de onde o fluxo for cortado. $\mathrm{O}$ interessante ressalta, é que o ponto de corte é definido por um fator exógeno à rede desta invenção: é o potencial comerciável de um híbrido patenteável que define onde se localizam os pontos de "origem" e o "fim" da rede que o criou. A própria definição da ideia de propriedade, portanto, varia conforme as relaçóes a serem consideradas na rede de produção de um bem (Strathern, 1996: 518$524)^{13}$. A quem pertence o patrimônio cultural mangueirense é uma controvérsia semelhante à da patente descrita por Strathern (1996). A disputa, portanto, não se distingue do objeto disputado, a saber, o patrimônio cultural. Como vimos, este é "criado" por meio de uma rede envolvendo todo um trabalho de "resgate cultural" e "registro". Participei deste "trabalho" - ou "ajuda" - participando da criação de material audiovisual, textos de divulgação do CCC e, entre outros produtos, uma dissertação. Ao mesmo tempo, freqüentei casas de "tias" e vovós”. E à medida que fui sendo incorporada à família verde e rosa, a linguagem acionada foi deixando de ser a do "direito", ou do "roubo". Sob a perspectiva da "família" à qual eu era incluída, minha "criação" abria outra via de "pertencimento", outro modo de relação; não se definia em oposição a uma sociedade englobante, mas sim na própria negação do que este englobamento pressupóe. Assim, não se trata aqui de ver o "direito" e o "compromisso" em oposição ao "afeto" e o "sangue", mas de buscar combiná-los ao modo da árvore verde e rosa. 
"Eu herdei de meus avós essa difícil missão de manter viva a nossa cultura, mas também herdei a rede de relaçóes que me ajudam nessa missão", repete Nilcemar. A atividade de manutenção da cultura mangueirense é, nas suas palavras, uma herança indissociável de sua vida; como ela mesma diz, indissociável de sua "natureza". "Ser da comunidade" tem, na "natureza" de Nilcemar, uma dimensão temporal particular - é resultado de um agenciamento que atualiza relaçóes anteriores à sua existência. Quando eu, pesquisadora "da sociedade", ajudo-a a "manter viva a cultura" (criando relaçôes com as "tias" e tornando-as "registro"), faço conexôes com uma determinada "rede" que integra empresas midiáticas, aparatos institucionais, "auto-estima”, "pobreza”, "mercado", "Estado", lojas de discos, livrarias, projetos sócio-culturais, pessoas, etc. Tal rede dá visibilidade a um "patrimônio cultural", torna-o "vivo" porque torna pública uma herança pessoal. Para isto, sugiro que a produção de conhecimento sobre a "comunidade" náo seja observada como parte submetida ao que se produz na "sociedade", mas, ao contrário, que seja ao menos espiada por através das brechas por onde esta última estabelece, em seus próprios termos, as relaçóes "socioculturais" com a primeira.

A native anthropology of the green-and-pink family or native concept. Why see rhizome where we are shown a mango tree?

abstract when beginning the fieldwork at Morro da Mangueira, I heard: "you have to commit yourself, you have to give something back to the community". And they told me that the "cultural patrimony of the Mangueira" has been "stolen" by "people from the society". And, by articulating notions of "community" and "society", the explained to me that "Mangueira is a family". This paper explores this "mangueirense" discourse, heard mostly at spaces of encounter of "community" and "society". Where the notion of "a green and pink family" functions as an axis from which concepts of "cultural patrimony", "community" and "society" are recomposed; concepts that characterize social sciences discursive production. This particular idea of a "family", composed by non-consanguineous relationships, frequently described as "a tree plenty of fruit" puts in action a particular model of relation to otherness, bringing up in the analysis tools as those of network and rhizome. But, why should we see a rhizome where they are showing us a tree?

keywords Morro da Mangueira. Cultural Patrimony. Native Concept. Slum. Family. Network

\section{Notas}

1. Desenvolvo aqui o argumento de minha pesquisa para dissertação de mestrado (Cerqueira, 2006) e agradeço às contribuiçóes dos membros da banca: Eduardo Viveiros de Castro (o qual formulou a questão que dá nome ao artigo), Antonádia Borges e Marcio Goldman (orientador). Contudo, o texto a seguir, como de praxe, é de minha exclusiva responsabilidade.

2. "Morro da Mangueira" é o termo usado em referência ao complexo de moradias situadas em dois morros, Mangueira e Telégrafo, no bairro de São Cristóvão, zona norte do Rio de Janeiro. A área, cuja ocupação é em parte considerada irregular pela legislação vigente, hoje é reconhecida pelas demarcaçôes administrativas da cidade como "bairro da Mangueira" (integrando o programa "Favela-Bairro"), e será aqui designada ora "morro", ora "Mangueira", conforme o uso local. Embora estes termos sejam freqüentemente entendidos como sinônimos da fórmula "comunidade da Mangueira", o termo "comunidade" assume aqui denotação mais ampla, articulando-se às vezes, por exemplo, a uma ideia de identidade negra tâo ampla quanto controversa nas delimitaçôes de suas fronteiras.

3. A expressão "família mangueirense" já fora ricamente descrita por Goldwasser (1975). Da mesma forma, vale notar que Sherrif (1999) antecipou alguns dos elementos encontrados em minha pesquisa etnográfica ao descrever (em um universo similar ao Morro da Mangueira) como a expressão "roubo do carnaval" era utilizada para qualificar os processos ligados à transformação de uma atividade local em um produto de consumo para quem vem "de fora". Por 
fim, vale mencionar o trabalho de Cavalcanti (1999, p.27), que, de maneira não muito distante da apresentada aqui, propóe alargar a noção de "pensamento social" de modo a incluir os enredos e sambas-enredo do carnaval carioca como "um dos lugares de construçấo da temática racial”.

4. As aspas simples indicam citaçôes de frases, fórmulas e conceitos nativos; as aspas duplas delimitam ora termos que, pelo excesso de uso, aparecem frequentemente no discurso antropológico como noçōes "auto-evidentes" (cf. Strathern, 1996), ora trechos e conceitos de autores citados. Para facilitar a fluidez da leitura, contudo, não usarei as aspas quando já houver sido explicitado que uma determinada palavra deve assumir lugar de conceito ou que constitua uma fórmula nativa determinante para a argumentaçáo.

5. Sobre este problema, muitas vezes tratado sob a rubrica da "invenção da cultura", ver, entre outros, Agier (2001); Briggs (1996); Costa (2002); Fry (2001); Gonçalves (2005); Handler (1994); Hobsbawn \& Ranger (1984); McCallum (1996); Serres (1997); Thomas (1992).

6. Para uma elaboração a respeito das configurações de casas de uma mesma comunidade como formas de mapeamentos dos modos de morar e se relacionar, conferir Louis Marcelin (1996).

7. Sobre os "projetos sociais" da Mangueira, ver entre outros, Gonçalvez (2003) e Chinelli (1995), entre outros.

8. O importante papel da mulher nos processos de "criação" de patrimônios culturais mangueirenses mereceria elaboração mais atenta. Sobre o tema, pode-se conferir Chinelli (1995: 102-103), Moura (1988), Moura (1983) e Velloso (1990, p. 207 - 228).

9. Nilcemar conta que o filho adotivo de Zica e de Cartola foi verbalmente deserdado por Zica depois de uma série de desavenças com esta. Hoje, o tio adotivo recebe parte dos direitos autorais de Cartola, mas briga na justiça para ganhar "direitos maiores", o que se complica pelo fato de ter sido registrado como filho biológico de Cartola; sendo este estéril, invalida-se o registro. Nilcemar cuida para evitar que os restos mortais do avô não-consanguíneo sejam exumados até que se encerre o caso.

10. Este trabalho de "resgate" certamente prosseguia a despeito de minha presença. No ano seguinte ao término de minha pesquisa, Vovó Lucíola foi destaque do desfile da Mangueira e se tornou uma celebridade, sendo citada em todas as notícias que os veículos de comunicação traziam sobre o carnaval mangueirense daquele ano. Para falar como um mangueirense, Lucíola mostrava ser um "patrimônio cultural".
11. Na quadra de ensaios da Escola de Samba da Mangueira, o que chamo de "transformaçáo" pode ser entendido como um mecanismo ritual no sentido formulado por Da Matta (1979), onde o que este chama de "teatralização" da sociedade brasileira "salienta o caráter domesticado da transmutaçáo de pobre em nobre" (Da Matta, 1979, p. 46). Comparando a parada militar do dia Sete de Setembro ao desfile carnavalesco no Rio de Janeiro, o autor mostra que, enquanto, na primeira, a hierarquização é reafirmada, no segundo, "as posiçōes sociais ocupadas no quotidiano são neutralizadas ou invertidas: os rituais populares são ritos que objetivam o encontro, não a separaçáo" (idem, p. 47). Esta ideia aproxima-se fortemente da noção de "parentesco afetivo" apresentada aqui, com a diferença de que não estamos falando necessariamente de um momento ritual, mas de um modelo de relação que se reproduz cotidianamente nas casas mangueirenses.

12. O problema da proximidade desconfortável, aliás, não se limita às ciências "sociais"; nada mais gerador de controvérsias do que os modos como as relaçōes humanas ("políticas") afetam e são afetadas pelas descobertas científicas da "natureza". E se a ciência tornou-se co-extensiva ao resto das interaçôes "sociais", só podemos olhar para estas como "formigas míopes", diz Bruno Latour (2006: 213), em sua versão da " $A c$ tor-Network-Theory" ("ANT"). As formigas inspiram Latour a adotar, em sua formulação da noção de rede, a sigla "ANT" (em inglês, "formiga") propondo assim, ao invés do volume, da hierarquia, um modo "achatado" de ver as coisas (Latour, 2006: 213).

13. O argumento de Strathern (1996) aproxima-se do que foi formulado no Anti-Édipo de Deleuze e Guattari (1972, p.12): “Todo "objeto" supóe a continuidade de um fluxo, todo fluxo, a fragmentação do objeto. Sem dúvida, cada máquina-órgão interpreta o mundo inteiro segundo o próprio fluxo dela, de acordo com a energia que flui dela: o olho interpreta tudo nos termos do ver - o falar, o ouvir, o cagar, o trepar... Mas sempre uma conexão se estabelece com uma outra máquina, em uma transversal onde a primeira corta o fluxo da outra, ou "vê" seu fluxo cortado pela outra”. A coincidência entre as formulaçôes de Strathern (1996) e de Deleuze e Guattari (1972) é interessante não apenas porque enriquece a reflexão sobre a noção de rede, mas também porque é ela mesma uma coincidência possibilitada por uma espécie de caminho-rizoma. Vejamos: a ANT formulada por Latour (2006) é referida a uma tradição filosófica em 
que a noçấo de rede se associa ao conceito rizoma, de Deleuze e Guattari (1972). E se o resultado desta associação ganha ressalvas de Strathern (1996), é a partir de uma ideia de fluxo e corte muito similar à desses filósofos que a autora dá visibilidade a certas implicaçóes teóricas do conceito latouriano de rede.

\section{Referências bibliográficas}

AGIER, Michel. Distúrbios identitários em tempos de Globalizaçáo. Mana. Estudos de Antropologia Social. 7(2): 7-33, 2001.

BAMFORD, Sandra. Conceiving Relatedness: non-substancial relations among the Kamea of Papua New Guinea. Journal of Royal Anthropological Institute (N.S.) 10: 287-306, 2004.

BODENHORN, Bárbara. "'He used to be my relative': exploring the bases of relatedness among Inupiat of northern Alaska”. In: Carsten, Janet (ed.). Cultures of relatedness. New approaches to the study of kinship. Cambridge: Cambridge University Press. 2000. p. 128-149.

BRIGGS, Charles. The Politics of Discursive Authority in Research on the 'Invention of Tradition'. Cultural Anthropology, 11(4): 435-469, 1996.

CAVALCANTI, Maria Laura Viveiros de Castro. O rito e o tempo: ensaios sobre o carnaval. Rio de Janeiro: Civilização Brasileira, 1999.

CERQUEIRA, Ana Carneiro. "Que é feito de você". Mercadoria, valor e alma em um centro cultural da Mangueira. Dissertação de Mestrado - PPGAS,Museu Nacional,Universidade Federal do Rio de Janeiro, Rio de Janeiro, 2006.

CHINELLI, Filippina. O projeto pedagógico das escolas de samba e o acesso à cidadania: o caso da Mangueira. Boletim do Laboratório de Pesquisa Social. Rio de Janeiro: Ifcs/UFRJ, n. 8, 1992.

COSTA, Sérgio. "Desigualdades raciais e identidades culturais". In: As cores de Ercília: esfera pública, democracia, configuraçōes pós-nacionais. Belo Horizonte: Editora UFMG, 2002.

DA MATTA, Roberto. Carnaval, Malandros e Heróis: para uma sociologia do dilema brasileiro. Rio de Janeiro: Zahar, 1979.

DELEUZE, Gilles. "Qu'este-ce qu'un Dispositif". In: Deux Régimes de Fous. Paris: Les Editions de Minuit, 2003.

DELEUZE, Gilles e GUATTARI, Félix. "Introdução : Rizoma”. In: Mil Platôs: capitalismo e esquizofrenia. São Paulo: Editora 34, 2004.
. L"Anti Oedipe. Paris: Minuit, 1972.

EDWARDS, Jeanette. Born and Bread. Oxford: Oxford University Press, 2000.

FRY, Peter. "Feijoada e Soul Food 25 anos depois". In: Fazendo Antropologia no Brasil. Neide Oterci; Peter Fry e Miriam Goldenberg (orgs.). Rio de Janeiro: DP\&A Editora, 2001.

GOLDWASSER, Maria Júlia. O Palácio do Samba. Rio de Janeiro: Zahar, 1975.

GONÇALVEZ, Maria Alice Rezende. A Vila Olímpica da Verde e rosa. Rio de Janeiro: Editora FGV, 2003.

GONÇALVES, José Reginaldo Santos. "Os limites do patrimônio” In: Lima Filho, Manuel Ferreira; Beltrão, J Felipe e Eckert, Cornélia (orgs.) Antropologia e Patrimônio Cultural: diálogos e desafios contemporâneos (Associação Brasileira de Antropologia). Blumenau: Nova Letra 2007.

Ressonância, materialidade e subjetividade: As culturas como patrimônios. Horizontes Antropológicos, ano 11, n. 23, p. 15-36, 2005.

HANDLER, Richard. "Is Identity a Useful Cross-Cultural Concept?”. In: J. Gillis (ed.) Commemorations: The Politics of National Identity. Princeton: Princeton University Press, 1994.

HERZFELD, Michael. Cultural Intimacy. Social Poetics in the Nation-State. New York \&London: Routledge, 1996.

HOBSBAWN, Eric e RANGER, Terence. A Invenção das Tradiçôes. Rio de Janeiro: Paz e Terra, 1984.

LATOUR, Bruno. Changer de société. Refaire de la sociologie. Paris : Éditions La Découverte, 2006.

LÉVI-STRAUSS, Claude. O Pensamento Selvagem. São Paulo: Papirus (4a ed.), 2004 [1962].

MARCELIN, Louis Herns. Linvention de la Famille AfroAméricaine: Famille, Parenté et Domesticité parmi les Noirs du Recôncavo da Babia, Brésil. Rio de Janeiro: PPGAS - Museu Nacional/UFRJ (Tese de Doutorado), 1996.

MARCUS, George E. "A estética contemporânea do trabalho de campo na arte e na antropologia: experiências em colaboração e intervençáo". In: Barbosa, Andréa, Teodoro da Cunha, Edgar e Hikiji, Rose Satiko Gitirana (orgs.) Imagem-conhecimento. São Paulo: Papirus Editora, 2009

MCCALLUM, Cecília. Resisting Brazil: perspectives on Local Nationalism. Ethnos. Vol 61: 3-4, 1996.

MOURA, Roberto. Tia Ciata: A pequena África no Rio de Janeiro. Rio de Janeiro: Fundação Nacional de Arte, 1983.

MOURA, Roberto. Cartola, Todo Tempo Que Eu Viver. Rio de Janeiro: Corisco Edições, 1988. 
SAHLINS, Marshall. "A Tristeza da Doçura, ou a Antropologia Nativa da Cosmologia Ocidental”. In: Cultura na Prática. Rio de Janeiro: Editora UFRJ, 2004 [1996].

SERRES, Michel. "O que é identidade?". Le Monde de L'Éducation et de la Formation (mimeo), 1997.

SHERRIF, Robin E. The Theft of Carnaval: National Spectacle and Racial Politcs in Rio de Janeiro. Cultural Anthropology 14(1):3-28, 1999.

STRATHERN, Marilyn. "The Ethnographic Effect I". In: Property, Substance and Effect. Anthropological Essays on Persons and Things (Ch. 4). London: Athlone Press, 1999.
. Cutting the Network. Journal of the Royal Anthropological Institute 2 (3): 517-535, 1996.

THOMAS, Nicolas. The inversions of tradition. American Ethnologist, vol. 19, n. 2, maio 1992, pp. 213-232, 1992.

VELLOSO, Mônica Pimenta. As tias baianas tomam conta do pedaço: espaço e identidade cultural no Rio de Janeiro. Estudos Históricos, vol. 3, n. 3, pp 207-228, 1990.

WAGNER, Roy. "Culture as Creativity". In: The Invention of Culture. Chicago: The University of Chicago Press, pp 17-34, 1981

WILLIS, P. e TRONDMAN, M. Manifesto for Ethnography. Ethnography 1(1) 2000): 5-16, 2000.

\section{autora Ana Carneiro}

Pós-doutoranda em Antropologia Social / MN- UFRJ

Recebido em 17/03/2011

Aceito para publicação em 26/09/2011 